\title{
Effects of beta-glucan on protection of young and aged rats from renal ischemia and reperfusion injury
}

\author{
Esrefoglu $\mathrm{M}^{1}$, Tok $\mathrm{OE}^{1}$, Aydin $\mathrm{MS}^{1}$, Iraz $\mathrm{M}^{2}$, Ozer $\mathrm{OF}^{3}$, Selek $\mathrm{S}^{3}$, Iraz $\mathrm{M}^{4}$ \\ Bezmialem Vakif University Faculty of Medicine, Dept. of Histology and Embryology, Istanbul, \\ Turkey.mdrmukaddes@yahoo.com
}

\begin{abstract}
BACKGROUND: Ischemia-reperfusion injury is one of the leading causes of acute renal failure which is a common clinical event leading to development of chronic kidney disease and a high mortality; especially in elderly people. $\beta$-glucans are glucose polymer groups with free-radical scavenger, macrophage activator, and immune defense inducer functions. We designed this study to determine the possible protective effects of $\beta$-glucan against renal ischemia-reperfusion injury comparatively in young and aged rats.

METHODS: Rats were assigned to the following groups: Young and aged sham, young and aged ischemia-reperfusion, young and aged $\beta$-glucan, young and aged ischemia-reperfusion $+\beta$-glucan. At the end of the experiment, following collection of blood samples, rats were sacrificed and kidneys were removed for histopathological and biochemical examination.

RESULTS: Mean tissue histopathological damage scores of young $\beta$-glucan group was lower than that of young ischemia-reperfusion group, and of aged $\beta$-glucan group was lower than that of aged ischemia-reperfusion group. Urea and creatinine levels of young and aged of sham group and $\beta$-glucan administered groups were all lower than those of ischemia-reperfusion and $\beta$-glucan+ischemia-reperfusion groups. Oxidative stress indexes of ischemia-reperfusion groups were increased however; oxidative stress indexes of $\beta$-glucan administered to young and aged rats were lower than those of ischemia-reperfusion groups.

CONCLUSIONS: We conclude that $\beta$-glucan is effective to protect kidneys from ischemia-reperfusion-induced oxidative damage, especially in young rats (Fig. 6, Ref. 45). Text in PDF www.elis.sk.

KEY WORDS: oxidative damage, beta-glucan, ischemia and reperfusion, kidney, aged rat.
\end{abstract}

\section{Introduction}

Ischemic acute renal failure (ARF) is a common clinical event leading to development of chronic kidney disease and a high mortality. ARF has a higher incidence in elderly people than younger ones $(1,2)$. Ischemic ARF is a complex syndrome involving renal vasoconstriction, tubular necrosis and glomerular injury (3). Much of the tubular and glomerular dysfunction has been postulated to occur during the reperfusion period following anoxia, ATP depletion and impaired calcium regulation, generation of ROS and production of pro-inflammatory cytokines $(4,5)$. Ex-

${ }^{1}$ Bezmialem Vakif University Faculty of Medicine, Department of Histology and Embryology, Istanbul, Turkey, ${ }^{2}$ Medeniyet University Faculty of Medicine, Department of Pharmacology, Istanbul, Turkey, ${ }^{3}$ Bezmialem Vakif University Faculty of Medicine, Department of Medical Biochemistry, Istanbul, Turkey, and ${ }^{4}$ Bezmialem Vakif University Faculty of Medicine, Department of Microbiology, Istanbul, Turkey

Address for correspondence: M. Esrefoglu, Prof, MD, Bezmialem Vakif University, Medical Faculty, Department of Histology and Embryology, 34093, Istanbul, Turkey.

Phone: +90.5323465239 , Fax: +90.2125336855

Acknowledgement: This study was supported by Bezmialem Vakif University Scientific Research Committee (\#3.2014/46). perimental studies of the pathogenesis of renal ischemia-reperfusion (I/R) have most commonly utilized the model of renal artery clamping; either by performing unilateral nephrectomy followed by clamping the renal artery of the contra-lateral kidney (3) or by clamping both renal pedicles $(6,7)$. Post-ischemic renal injury in this model has been shown to be very similar to human ischemic renal injury, including that secondary to cold kidney storage prior to transplantation (8).

Beta-glucans are glucose polymer groups that form a fibrotic extracellular matrix in the cell walls of yeast (9), plants (10), and some bacteria (11). Currently, different types of $\beta$-glucans serve as immunomodulators that activate cellular and humoral components of the host immune system (12). Several studies indicate further possible effects: activation of macrophages (13) ; precipitation of wound healing by increasing wound-growth factors (9) ; increased defense mechanisms against bacterial, viral, fungal, and parasitic infections (14); and protective effects against oxidative damage in DNA through an effective free-radical scavenger function (15). Limited studies have been performed about the effects of $\beta$-glucan on renal I/R. To our knowledge this is the first study examining protective effects of $\beta$-glucan comparatively in young and aged rats. In this study, effects of $\beta$-glucan on renal I/R injury were investigated in young and aged Sprague Dawley rats by using histological and biochemical methods. 


\section{Material and methods}

Animals

In this study 56 female Sprague-Dawley rats were used. All rats were housed in plastic cages in an experimental animal room (22-24 ${ }^{\circ} \mathrm{C}, 55-70 \%$ humidity, $12-\mathrm{h}$ light/dark cycle). They were fed a standard laboratory diet, and drinking water was available ad libitum throughout the experiment. This study's experimental procedures were approved by the Institutional Review Board and Animal Use Committee of the Bezmialem Vakif University (\#2013/232).

\section{Groups}

56 female Sprague-Dawley rats were randomly assigned to two main groups as young ( 4 months old, $300-350 \mathrm{~g} ; \mathrm{n}=24$ ) and aged groups (16 months old, $350-450 \mathrm{~g} ; \mathrm{n}=32$ ). Groups were designed as follows: Young sham (YS) and aged sham (AS), young $\mathrm{I} / \mathrm{R}(\mathrm{YI})$ and aged I/R (AI), young $\beta$-glucan (YB) and aged $\beta$-glucan $(A B)$, young $\mathrm{I} / \mathrm{R}+\beta$-glucan $(\mathrm{YBI})$ and aged $\mathrm{I} / \mathrm{R}+\beta$-glucan $(\mathrm{ABI})$.

\section{Experimental protocol}

Animals in all experimental groups were anesthetized using intraperitoneally administered ketamine/xylasine. The rats underwent right nephrectomy and were subjected to $45 \mathrm{~min}$ renal artery occlusion followed by 1 hour reperfusion period in $\mathrm{I} / \mathrm{R}$ performed groups as described by Weight et al (16). In $\beta$-glucan administered groups, $\beta$-glucan (Imuneks ; Mustafa Nevzat, Istanbul, Turkey) was administered by gavages at a dose of 50 $\mathrm{mg} / \mathrm{bw} /$ day for 10 days prior to the surgery. Sham-operated rats underwent laparotomy without performing I/R process. In all of the groups right nephrectomy was performed at the beginning of the surgical procedure. At the end of the experiment, following collection of blood samples from the heart, rats were sacrificed and kidneys were removed for histopathological and biochemical examination.

\section{Histopathological assessment}

For light microscopic investigations, samples were placed in $10 \%$ formaldehyde, dehydrated in ascending alcohol series (70 $\%, 90 \%, 96 \%$ and $100 \%$ ), cleared in xylene and embedded in paraffin. Tissue sections $(5 \mu \mathrm{m})$ were stained with hematoxylin and eosin (H\&E) and examined with a light microscope (Nikon Eclipse i5, Tokyo, Japan) coupled with a camera (Nikon, DS-Filc). Histopathological changes including tubular degeneration (dilatation and atrophy), vacuolization, tubular necrosis, glomerulosclerosis, hemorrhage, capillary dilatation and congestion, and intercellular edema were evaluated and graded as: 0 : absent ; 1 : mild ; 2 : moderate; and 3: severe with a maximum score of 21.
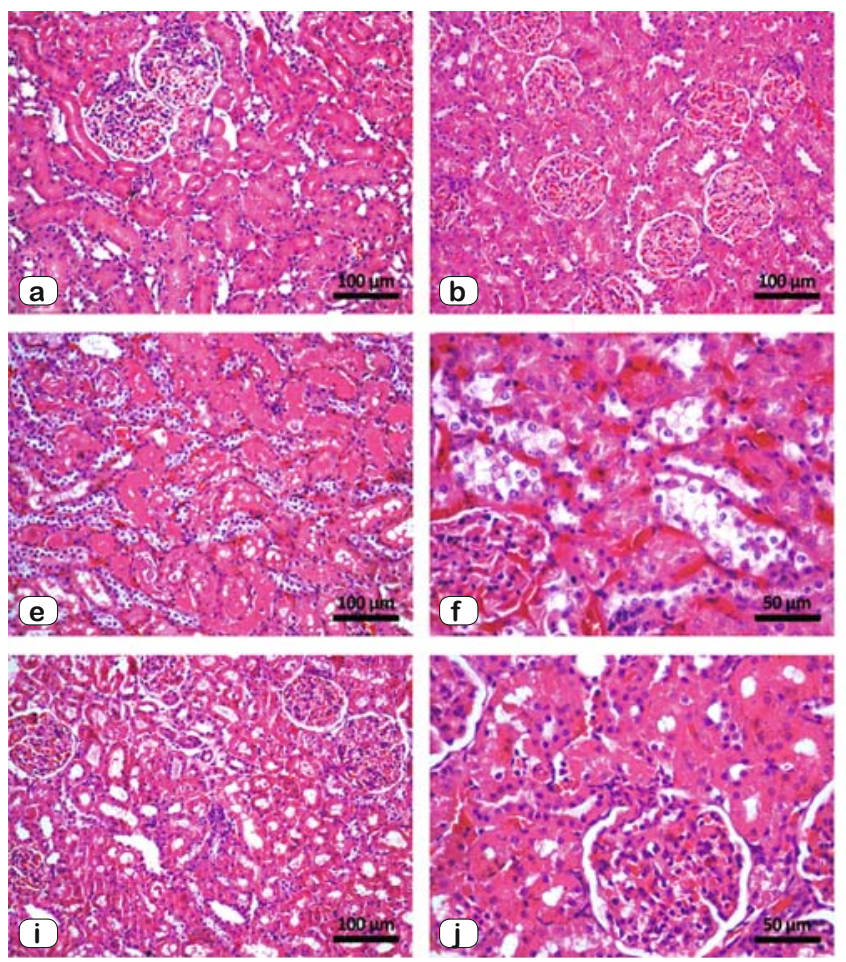
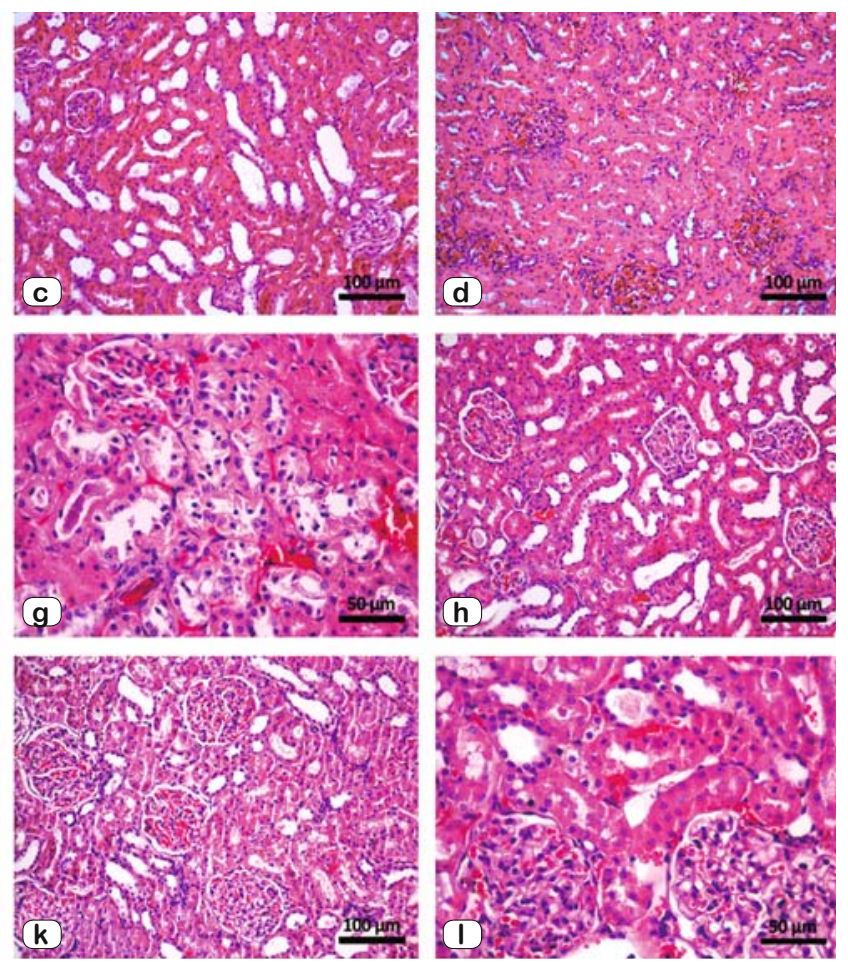

Fig. 1. Sections from young (a) and aged (b) $\beta$ glucan groups seem normal in histological appearance. Sections from young (c, d) and aged (e-h) I/R groups show many alterations including tubular degeneration (including dilatation and atrophy) (c, $g$, h), vacuolization and intracellular edema (f, g), tubular necrosis (d, e, g), glomerulosclerosis (d, g), hemorrhage (f, g), capillary dilatation and congestion (f). Sections from young $(i, j)$ and aged $(k, l) ~ I / R+\beta$ glucan groups appeared pretty normal except mild tubular dilatation $(i, k)$ and focal necrosis $(j)$ in histological appearance. Hematoxylin and eosin staining (a, b, c, d, e, h, l, k: bar = $100 \mu \mathrm{m}$, original magnification, x200; f, g, j, l: bar $=50 \mu \mathrm{m}$, original

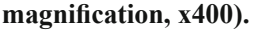


530-538

\section{Biochemical analysis}

Creatinine and urea levels were determined by autoanalyser (Roche cobas C506 oto autoanalyser ; Germany) using commercially available assay kits. Total oxidant status and total antioxidant capacity (TAC and TOS) (17-19), thiol (20), myeloperoxidase (MPO) (21), paraoxanase (PON1) (22), catalase (CAT) (23) and aryl esterase (ARES) (24) were measured in serum and tissue by the methods previously described. Additionally, the ratio percentage of TOS level to TAC level gave the OSI, an indicator of the degree of oxidative stress (25). The levels of C-reactive protein (CRP) in plasma were quantified using enzyme-linked immunosorbent assays (ELISA) kits (Rat CRP Elisa Kit, Assaypro, USA.) according to the manufacturer's instructions. IL- 6 and IL-8 levels were measured with ELISA kits (Rat IL-6 and IL-8 Platinum ELI$\mathrm{SA}$, eBioscience, Bender Medysystems GmbH, Vienna, Austria).

\section{Statistical analysis}

All data are expressed as means \pm s.d. All data were compared by one-way ANOVA followed by Tukey multiple comparison tests. Values of $p<0.05$ were regarded as significant. Statistical analysis was performed using a commercially available software program (GraphPad, Prism 6, San Diego, CA, USA).

\section{Results}

\section{Histopathological analysis}

Histological picture of right kidneys (removed by nephrectomy) of all of the young and aged rats and left kidneys of young and aged sham operated and $\beta$-glucan administered rats were normal or nearly normal (aged ones) (Figs 1a, b). Mean tissue HDSs of young sham operated group was lower than that of young I/R group $(\mathrm{p}<$ $0.001)$. I/R resulted in some histopathological changes including tubular degeneration (including dilatation and atrophy) (Figs 1c, $\mathrm{g}, \mathrm{h}$ ), vacuolization and intracellular edema (Figs 1f, g), tubular necrosis (Figs 1d, e, g), glomerulosclerosis (Figs 1d, g), hemorrhage (Figs 1f, g), capillary dilatation and congestion (Fig. 1f), and intercellular edema in both young and aged rats. Mean HDSs of sham operated young and old groups were $0.5 \pm 0.83$ and $1 \pm 0.57$ ; respectively whereas of young and aged I/R groups were $8 \pm 1.67$ and $4.86 \pm 1.34$; respectively. Mean HDSs of young $\beta$-glucan $+\mathrm{I} / \mathrm{R}$ group was $1.83 \pm 0.75$ and of aged $\beta$-glucan $+\mathrm{I} / \mathrm{R}$ group was 2.75 \pm 1.16 . Thus, mean tissue HDSs of young and aged $\beta$-glucan $+\mathrm{I} / \mathrm{R}$ groups were lower than those of young and aged I/R groups. The findings we observed in the sections of young and aged animals from I/R groups were not prominent in the sections of young and aged rats from $\mathrm{I} / \mathrm{R}+\beta$-glucan groups (Figs $1 \mathrm{i}-1$ ). Mean tissue HDSs of young $\beta$-glucan group was lower than that of young $I / R$ group and of aged $\beta$-glucan group was lower than that of aged I/R group ( $p<0.05$; for both). Mean tissue HDSs of right (nephrectomy) and left kidneys of all groups are summarized in Figure 2.

\section{Biochemical analysis}

Serum urea and creatinine levels of young and aged of sham group and $\beta$-glucan administered groups were all lower than those of $I / R$ and $\beta$-glucan $+I / R$ groups. Serum urea levels of young and aged $I / R$ groups were higher than those of young and aged $\beta$-glucan $+\mathrm{I} / \mathrm{R}$ groups. Significant differences in urea levels were detected between young and aged $\beta$-glucan administered groups and young and aged I/R performed groups $(\mathrm{p}<0.01, \mathrm{p}$ $<0.001$; respectively) (Fig. 3a). Significant differences in creatinine levels were detected between young and aged $\beta$-glucan administered groups and I/R performed groups $(\mathrm{p}<0.01)$. Creatinine level of young $\beta$-glucan was lower than that of young $\beta$-glucan $+\mathrm{I} / \mathrm{R}$ group $(\mathrm{p}<0.05)$ and of aged $\beta$-glucan was lower than that of young $\beta$-glucan $+\mathrm{I} / \mathrm{R}$ group $(\mathrm{p}<0.01)$ (Fig. $3 b)$. Serum ARES level of young sham group was higher than that of young I/R and $\beta$-glucan $+\mathrm{I} / \mathrm{R}$ groups $(\mathrm{p}<0.01)$ (Fig. $3 \mathrm{c})$. Serum PON activities of sham operated young and aged rats were higher than those of $\beta$-glucan, I/R and $\beta$-glucan $+\mathrm{I} / \mathrm{R}$ groups (Fig. $3 \mathrm{~d}$ ). Mean serum CAT activities and MPO activities of young and aged $\beta$-glucan administered groups were lower than those of $\mathrm{I} / \mathrm{R}$ and $\beta$-glucan $+\mathrm{I} / \mathrm{R}$ groups. Mean serum CAT activity of aged
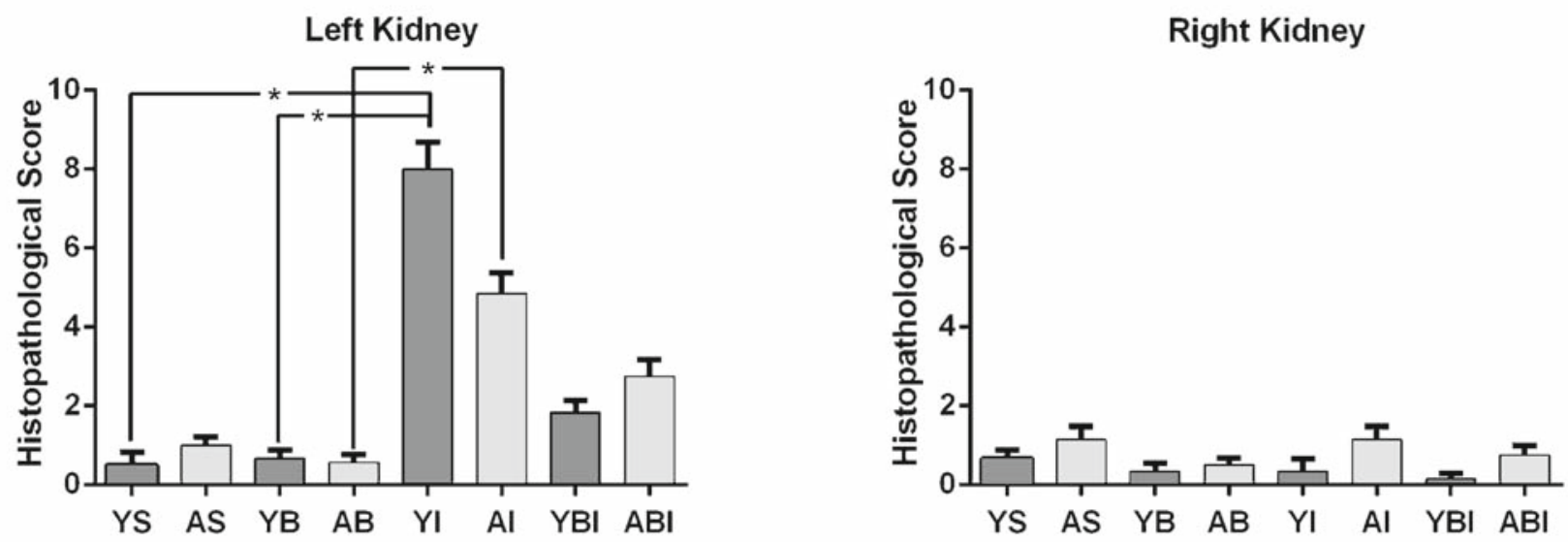

Fig. 2. Mean tissue histopathological scores of YS (young sham), AS (aged sham), YB (young $\beta$ glucan), AB (aged $\beta$ glucan), YI (young I/R), AI (aged I/R), YBI (young I/R+ $\beta$ glucan), ABI (aged I/R+ $\beta$ glucan) groups are summarized. Left kidneys and right (nephrectomy) kidneys. The data shown are means \pm s.d. $(* p<0.05)$. 

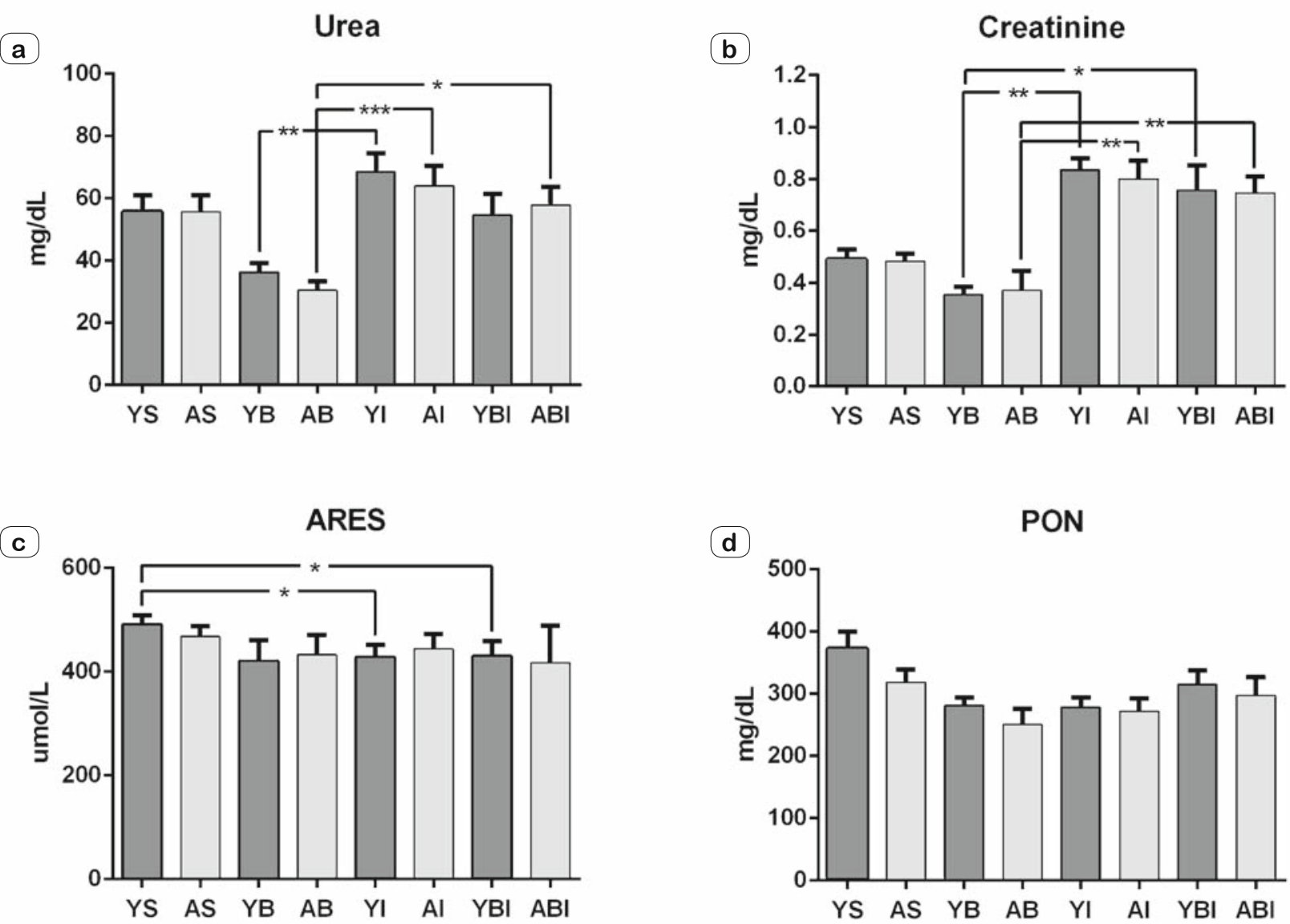

Fig. 3. Serum urea (a), creatinine (b), ARES (c) and PON (d) levels of all groups. The data shown are means \pm s.d. $\left({ }^{*} \mathbf{p}<0.05, * * \mathbf{p}<0.01, * * *\right.$ $\mathbf{p}<0.001$ ).

sham operated group was lower than that of aged I/R group ( $\mathrm{p}$ $<0.05)$. Mean tissue CAT activity of young I/R was lower than that of sham group, whereas mean tissue CAT activity of aged $\mathrm{I} / \mathrm{R}$ was higher than that of sham operated group. Additionally CAT activity of young sham-operated group was higher than that of $\beta$-glucan $+\mathrm{I} / \mathrm{R}$ group $(\mathrm{p}<0.05)$. Serum MPO activity of aged $\mathrm{I} / \mathrm{R}$ group was higher than that of sham-operated group $(p<0.05)$. Serum and tissue MPO activities of young and aged $\beta$-glucan $+\mathrm{I} / \mathrm{R}$ groups were lower than those of young and aged $\mathrm{I} / \mathrm{R}$ groups. Differences on tissue MPO activities among sham, $\mathrm{I} / \mathrm{R}$ and $\beta$-glucan $+\mathrm{I} / \mathrm{R}$ group were not statistically important. Serum and tissue CAT activities and MPO levels are summarized in Figure 4. Serum thiol levels of young and aged I/R groups were higher than those of $\beta$-glucan $+\mathrm{I} / \mathrm{R}$ groups. Serum thiol level of young sham group was higher than that of young $\beta$-glucan and young $\beta$-glucan $+\mathrm{I} / \mathrm{R}$ group $(\mathrm{p}<0.01, \mathrm{p}<0.05$; respectively). Serum thiol level of aged sham group was higher than that of aged $\beta$-glucan group $(\mathrm{p}<0.05)$ (Fig. 4). Tissue thiol level of young sham group was higher than that of $\beta$-glucan $+\mathrm{I} / \mathrm{R}(\mathrm{p}<0.05)$ (Fig. 4). Differences in serum TOS among groups were not significant (Fig. 4). Serum TAC of young and aged $\beta$-glucan $+\mathrm{I} / \mathrm{R}$ group were lower than those of young and aged sham-operated groups $(\mathrm{p}<$
0.05). TAC of aged I/R group was higher than that of $\beta$-glucan group $(p<0.05)$. TAC of aged sham group was higher than that of aged $\beta$-glucan group $(\mathrm{p}<0.05)$ (Fig. 4). Tissue TOS of young $\beta$-glucan $+\mathrm{I} / \mathrm{R}$ group was lower than that of $\mathrm{I} / \mathrm{R}$ group whereas tissue TOS of aged $\beta$-glucan $+\mathrm{I} / \mathrm{R}$ group was higher than that of I/R group. Additionally, TOS of aged $\beta$-glucan $+I / R$ group was higher than that of young $\beta$-glucan $+\mathrm{I} / \mathrm{R}$ group and aged sham-operated group $(\mathrm{p}<0.001 ; \mathrm{p}<0.05)$ (Fig. 4). Tissue TAC of young $\beta$-glucan $+\mathrm{I} / \mathrm{R}$ group was lower than that of sham-operated group $(p<0.001)$ (Fig. 4). Additionally, tissue OSIs of $\beta$-glucan $+\mathrm{I} / \mathrm{R}$ groups were lower than those of $\mathrm{I} / \mathrm{R}$ groups. Tissue OSIs of right kidneys (nephrectomy-performed) of young and aged rats were lower than those of lefts kidneys of I/R performed rats $(p<0.05$, $p<0.01$; respectively). Tissue OSIs of $\beta$-glucan administered young and aged rats were lower than those of $\mathrm{I} / \mathrm{R}$ performed rats $(\mathrm{p}<0.01)$ (Fig. 5).

Changes between the levels of CRP of young and aged I/R and $\mathrm{I} / \mathrm{R}+\beta$-glucan groups were not striking (Fig. 6a). IL-6 levels of I/R groups were higher than those of sham, $\beta$-glucan and $\mathrm{I} / \mathrm{R}+$ $\beta$-glucan groups (Fig. $6 \mathrm{~b}$ ). IL-8 levels of young I/R group were higher than those of young sham, $\beta$-glucan and $I / R+\beta$-glucan groups (Fig. 6c). 
530-538

SERUM
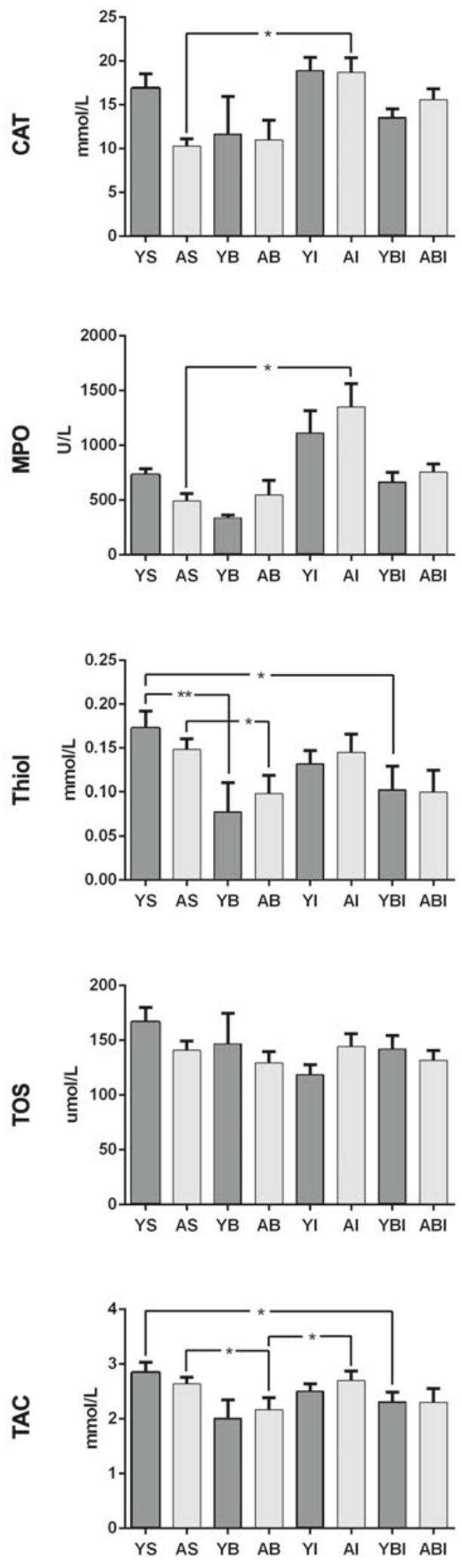

TISSUE
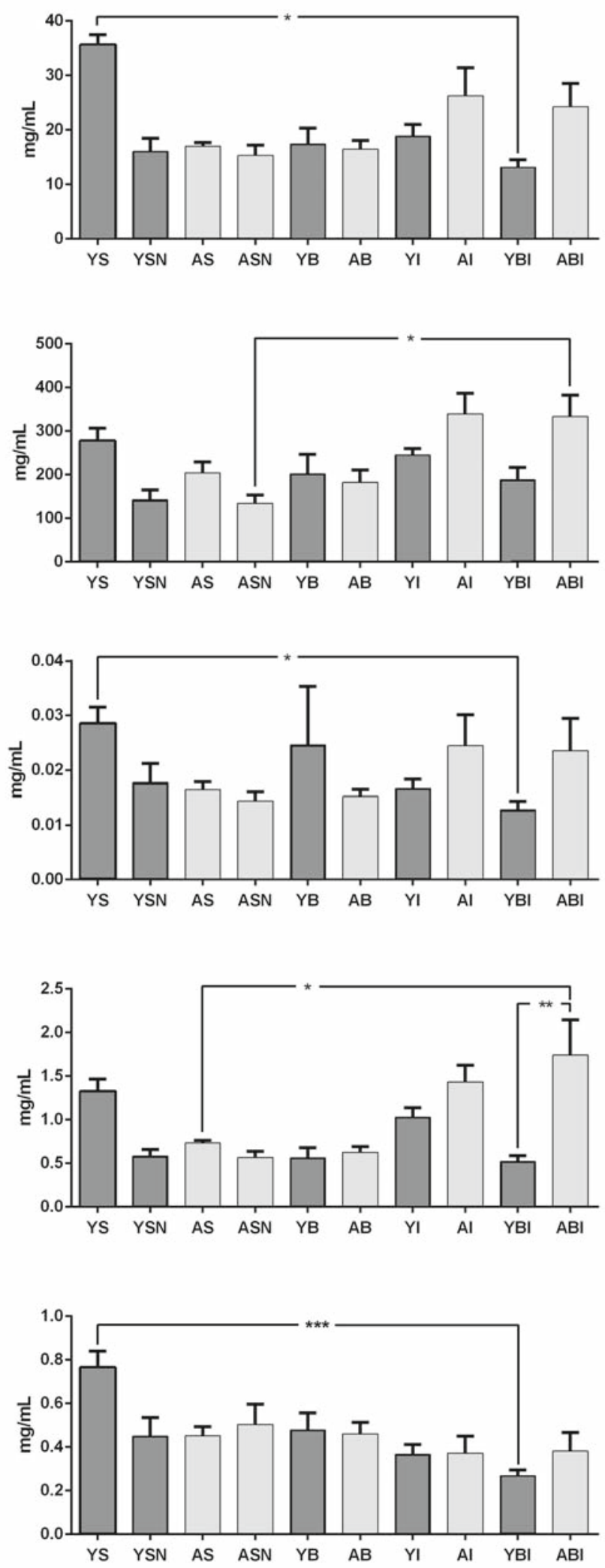

Fig. 4. Serum and tissue CAT, MPO, Thiol, TOS, TAC levels of all groups. The data shown are means \pm s.d. $\left({ }^{*} p<0.05,{ }^{* *} p<0.01, * * * p<0.001\right)$. 


\section{Tissue OSIs}



Fig. 5. Tissue oxidative stress indexes. The data shown are means \pm s.d. $\left({ }^{*} \mathrm{p}<0.05,{ }^{* *} \mathrm{p}<0.01, * * * \mathrm{p}<0.001\right)$.

\section{Discussion}

Ischemic acute renal failure (ARF) is a common clinical event leading to development of chronic kidney disease and transition from pre-existing chronic kidney disease to end-stage renal disease and a high mortality $(1,2)$. Ischemic ARF is a complex syndrome involving renal vasoconstriction, tubular necrosis and glomerular injury (3). In the present study we investigated the degree of renal damage by microscopic and biochemical methods in order to comprehend the protective capacity of $\beta$-glucan, a free-radical scavenger, macrophage activator and immune defense inducer in young and aged rats. Aged rats are more susceptible to I/R-induced renal failure, which may associate with the increased oxidative stress, increased histologic damage, and increased inflammation and tubulointerstitial fibrosis (2). The incidence of acute kidney injury in the elderly population has steadily increased in recent years. Functional recovery after acute kidney injury is impaired in the elderly. Although the exact mechanism underlying age-related differences is not well understood, it is known that aged rats exhibit reduced antioxidant potential and increased oxidative stress after I/R $(1,26)$. The results of Zhang et al (26) demonstrate that aged rats experience more severe reperfusion-induced injuries compared with young rats. Compared with young ischemia/reperfusion group, the contents of MDA were higher and the contents of SOD were lower in aged ischemia/reperfusion group. Kusaka et al (1) reported that serum BUN and Cre levels elevated after I/R were higher in aged $I / R$ rats than in young $I / R$ rats. Moreover, survival rate of the young $I / R$ group was higher than that of the aged $I / R$ group. Xu et al (2) reported that aged rats were more susceptible to the oxidative damage following $45 \mathrm{~min}$. ischemia and $12 \mathrm{wk}$. reperfusion. In the present study all of the rats, young and aged, survived during whole ischemia and reperfusion period. Mean HDSs of sham operated young and old groups were $0.5 \pm 0.83$ and $1 \pm 0.57$; respectively; whereas of young and aged I/R groups were $8 \pm 1.67$ and $4.86 \pm 1.34$; respectively. Mean tissue OSIs of young I/R group was lower than aged I/R group and of young I/R+ $\beta$-glucan group was lower than that of aged $\mathrm{I} / \mathrm{R}+\beta$-glucan group. Additionally, serum creatinine and urea levels were not higher in aged rats than in young rats. Thus we suggest that aged rats are more resistant to early $\mathrm{I} / \mathrm{R}$ injury than young ones in opposite to the previously reported data.

In our study, I/R resulted in some histopathological changes including tubular degeneration (including dilatation and atrophy), vacuolization and intracellular edema, tubular necrosis, glomerulosclerosis, hemorrhage, capillary dilatation and congestion, and intercellular edema, as excepted. However; these changes were more obvious in young rats. In $\beta$-glucan administered and $I / R$ performed groups, the mentioned alterations were reduced. The mean tissue HDSs of young and aged $\beta$-glucan $+\mathrm{I} / \mathrm{R}$ groups were lower than those of young and aged I/R groups ; respectively. HDSs of young $\beta$-glucan group was lower than that of young $I / R$ group, and of aged $\beta$-glucan group was lower than that of aged $\mathrm{I} / \mathrm{R}$ group $(\mathrm{p}<0.05)$.

Serum urea and creatinine levels of young and aged sham group and $\beta$-glucan administered groups were all lower than those of $I / R$ and $\beta$-glucan $+I / R$ groups. Serum urea and creatinine levels of young and aged $\mathrm{I} / \mathrm{R}$ groups were higher than those of all of the young and aged groups. Although serum creatinine and urea levels of $\beta$-glucan $+\mathrm{I} / \mathrm{R}$ groups were lower than those of $\mathrm{I} / \mathrm{R}$ groups, changes were not significant. We have some clues that $\beta$-glucan administration prior to $\mathrm{I} / \mathrm{R}$ is somewhat effective in reducing increased blood urea and creatinin levels. In fact, the low levels in $\beta$-glucan pretreated groups in comparison to sham groups were noteworthy. Having a low level of blood creatinine indicates nothing more than an efficient and effective kidney. We suggest
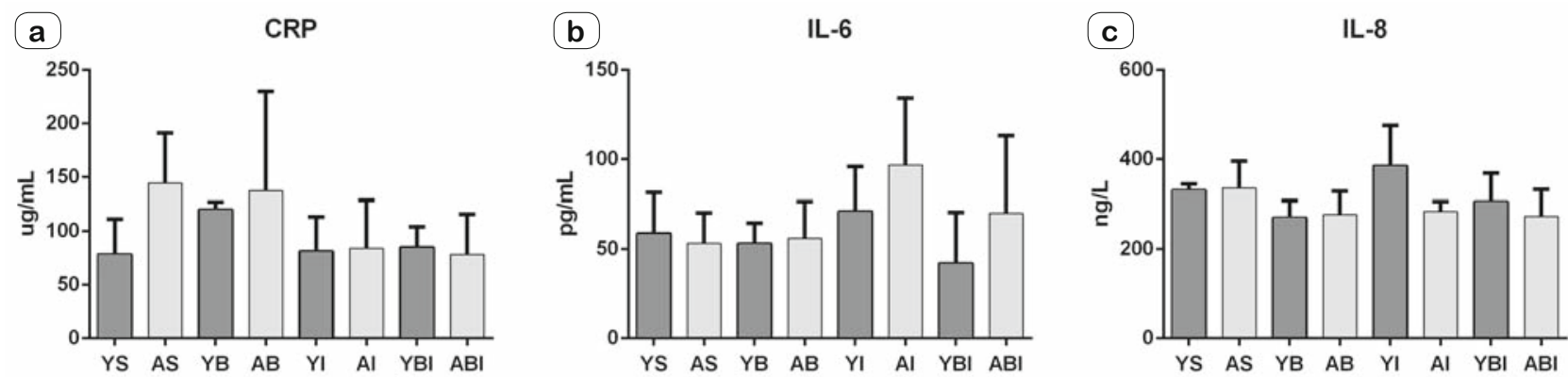

Fig. 6. Serum CRP (a), IL-6 (b) and IL-8 (c) levels of all groups. The data shown are means \pm s.d. 


\section{0-538}

that $\beta$-glucan administration simultaneous to $\mathrm{I} / \mathrm{R}$ might be more effective to support kidney functions. On the other hand, evaluation of these parameters later than several hours might be more meaningful for evaluating kidney functions.

It is well known that reperfusion following ischemia may cause additional damage and further complicate the injury through accumulation of ions, generation of ROS, endothelial dysfunction, platelet aggregation and immune activation (27). During the acute ischemia period, activation of the endothelium with increased permeability and expression of different adhesion molecules elicits an acute inflammatory response characterized by activation of neutrophils, which cause I/R-induced inflammatory cascades through the production and release of ROS and cytotoxic proteins including MPO into the extracellular fluid (27) and (28). The amount of antioxidant activity of $\beta$-glucan was influenced by the different physiologic properties (e.g., structure and molecular size) of $\beta$-glucan, which varied depending on the source and extraction method used. Furthermore, the hydroxyl scavenging activity of $\beta$-glucan has been found to be significantly higher than that of various polymers that are used as food additives (29). In recent years, oxidative damage has been shown to play an important role in pathogenesis of various diseases as well as aging. Thus, large numbers of antioxidant and free radical scavenger have been studied in terms of their therapeutic potency so far. We tried to evaluate oxidative stress by measuring serum and tissue TAC, TOS, thiol levels and CAT activities. Additionally, we evaluated OSIs by dividing mean TOS level to TAC level of each of the groups. Differences in serum TOS among groups were not significant. Serum TAC of young and aged $\beta$-glucan $+\mathrm{I} / \mathrm{R}$ group were lower than those of young and aged sham-operated groups. On the other hand, tissue TOS of young $\beta$-glucan $+\mathrm{I} / \mathrm{R}$ group was lower than that of I/R group whereas tissue TOS of aged $\beta$-glucan $+\mathrm{I} / \mathrm{R}$ group was higher than that of $\mathrm{I} / \mathrm{R}$ group. Additionally, TOS of aged $\beta$-glucan $+\mathrm{I} / \mathrm{R}$ group was higher than that of young $\beta$-glucan $+\mathrm{I} / \mathrm{R}$ group and aged sham-operated group. It was clear that $\beta$-glucan prevented young rats from I/R-induced oxidative stress rather than aged rats. Changes in tissue TAC levels were not generally significant. Solely, tissue TAC of young $\beta$-glucan + I/R group was lower than that of sham-operated group. Additionally, tissue OSIs of I/R groups were increased. The latter change implies that $I / R$ have resulted in either increase in TOS levels and/or decrease in TAC levels. Since OSI of young $\beta$-glucan administered and I/R performed rats than that of $I / R$ performed rats, it was clear that $\beta$-glucan administration was more effective in reducing oxidative stress in young rats than aged ones. In fact, mean histopathological score of young $\mathrm{I} / \mathrm{R}+\beta$-glucan group was lower than that of the aged $\mathrm{I} / \mathrm{R}+\beta$-glucan group. Moreover, although insignificant, serum and tissue thiol levels of $\mathrm{I} / \mathrm{R}$ performed groups were higher than those of $\mathrm{I} / \mathrm{R}$ performed and $\beta$-glucan administered groups. Recent results demonstrate that irrespective of their metabolic origin elevated thiols are associated with increased oxidative stress in plasma (30). Serum protein thiol levels are a direct measure of the in vivo reduction/oxidation (redox) status in humans, because thiols react readily with oxygen-containing free radicals to form disulfides. Moreover, serum thiols also reflect DNA repair capacity and the possible eventual accumulation of genetic damage, since a key DNA repair enzyme, poly ADP-ribose polymerase (PARP), is thiol/disulfide redox regulated (31). Considering the results of HDSs, OSIs, and mean serum end tissue thiol levels, we conclude that $\beta$-glucan is effective to protect kidneys from I/R-induced oxidative damage, especially in young rats.

Activity of tissue MPO, an enzyme that is found predominantly in the azurophilic granules of polymorphonuclear leukocytes (PMNs), is used as an indication of accumulation of neutrophils in inflamed tissues. Hypoperfusion occurring predominantly in the corticomedullary junction and outer medulla may directly contribute to leukocyte accumulation (32). Activated neutrophils are generally considered to be the principal effectors of renal I/R injury as they can release superoxide, which can be converted to hydroxyl radicals and NO that can combine with superoxide to form peroxynitrite (33). Activation of neutrophils causes I/R-induced inflammatory cascades through the production and release of ROS and cytotoxic proteins including MPO into the extracellular fluid $(27,28)$. Versteilen et al (34) reported early leukocytes, mostly PMNs, predominantly accumulated in the microvasculature of the corticomedullary junction and medulla in the first hour of reperfusion following $60 \mathrm{~min}$ ischemia. We did not detect leukocyte infiltration into the cortical or medullar tissue at the end of $\mathrm{I} / \mathrm{R}$ period. In fact, the differences in mean MPO activities of the groups were not striking. Behrends et al (35) reported tissue MPO activities of sham operated and ischemia performed groups were similar at the end of $45 \mathrm{~min}$ ischemia and $24 \mathrm{~h}$ reperfusion period. Koc et al (36) reported increased MPO activity at the end of 60 min ischemia and $24 \mathrm{~h}$ reperfusion period. In our study serum MPO activities of young and aged $\mathrm{I} / \mathrm{R}$ groups were higher than those of sham and $\mathrm{I} / \mathrm{R}+\beta$-glucan groups. The results indicate the neutrophil activation of the tissues of the whole body following renal $\mathrm{I} / \mathrm{R}$. It is well known that $\mathrm{I} / \mathrm{R}$ of any organ cause oxidative inflammatory response in various remote organs. We conclude that $\beta$-glucan administration even prior to $\mathrm{I} / \mathrm{R}$ inhibits neutrophil activation and MPO release thus reduces oxidative tissue damage.

Low levels of PON-1 and arylesterase (ARE), endogenous antioxidant enzymes, have been reported in situations in which reactive oxygen radicals increase and oxidative stress occurs (37, 38). PON1, an antioxidant and anti-atherogenic enzyme, is produced in the liver and secreted into the blood where it is incorporated into high density lipoprotein (HDL) and protects LDL and cellular membranes against lipid peroxidation (39). Although insignificant, we detected decreases in PON activities in I/R groups and slight elevations in $\mathrm{I} / \mathrm{R}+\beta$-glucan groups ; predominantly in young rats. Serum ARES level of young $(\mathrm{P}<0.01)$ and aged $\mathrm{I} / \mathrm{R}$ group was lower than that of sham groups. Beta-glucan administration more or less increased ARES activity in young but not aged rats following $\mathrm{I} / \mathrm{R}$.

CRP, IL-6, and IL-8 are soluble peptides associated with inflammation. CRP is an acute phase protein wherein its blood levels can rise dramatically within days after an inflammatory insult (40). This dynamic expression is regulated at the level of transcription, with IL- 6 being the main inducer of the CRP acute phase response (41). Although the liver is the major source of blood CRP (42) 
renal tubular epithelial cells also produce CRP (43) and so CRP actions in the kidney may be manifest even during periods of restricted blood flow (44). In our study changes between the levels of CRP of young and aged $\mathrm{I} / \mathrm{R}$ and $\mathrm{I} / \mathrm{R}+\beta$-glucan groups were not striking. However ; IL-6 levels of I/R groups were higher than those of sham, $\beta$-glucan and $\mathrm{I} / \mathrm{R}+\beta$-glucan groups. Additionally, IL-8 levels of young / $\mathrm{R}$ group were higher than those of sham, $\beta$-glucan and $\mathrm{I} / \mathrm{R}+\beta$-glucan groups. Beta-glucan administration reduced IL-6 levels as well as IL-8 levels in both young and aged rats. Yang $\mathrm{S}$ et al. reported elevated IL-6 and IL-8 levels following $45 \mathrm{~min}$ ischemia and 3 days reperfusion period (45).

As a conclusion, these results indicate that $\beta$-glucan is protective against I/R-induced renal damage ; especially for young rats. As a result of microscopic and biochemical data we suggest that $\beta$-glucan is a potential oxidative damage suppressor in protection from renal damage following $I / R$. Hereupon we plan to investigate therapeutic effects of long-term $\beta$-glucan administration following I/R.

\section{References}

1. Kusaka J, Koga H, Hagiwara S, Hasegawa A, Kudo K, Noguchi T. Age-dependent responses to renal ischemia-reperfusion injury. J Surg Res 2012; 172 (1): 153-158.

2. Xu X, Fan M, He X, Liu J, Qin J, Ye J. Aging aggravates long-term renal ischemia-reperfusion injury in a rat model. J Surg Res 2014; 187 (1): 289-296.

3. Chander V, Chopra K. Protective effect of nitric oxide pathway in resveratrol renal ischemia-reperfusion injury in rats. Arch Med Res 2006; 37 (1): 19-26.

4. Feitoza CQ, Camara NO, Pinheiro HS et al. Cyclooxygenase 1 and/or 2 blockade ameliorates the renal tissue damage triggered by ischemia and reperfusion injury. Int Immunopharmacol 2005; 5 (1): 79-84.

5. Legrand M, Mik EG, Johannes T, Payen D, Ince C. Renal hypoxia and dysoxia after reperfusion of the ischemic kidney. Mol Med 2008; 14 (7-8): 502-516.

6. Erbas H, Aydogdu N, Kaymak K. Effects of N-acetylcysteine on arginase, ornithine and nitric oxide in renal ischemia-reperfusion injury. Pharmacol Res 2004; 50 (5): 523-527.

7. Patel NS, Cuzzocrea S, Collino M et al. The role of cycloxygenase-2 in the rodent kidney following ischaemia/reperfusion injury in vivo. Eur J Pharmacol 2007; 562 (1-2): 148-154.

8. Nemoto T, Burne MJ, Daniels F et al. Small molecule selectin ligand inhibition improves outcome in ischemic acute renal failure. Kidney Int 2001; 60 (6): 2205-2214

9. Ross GD, Vetvicka V, Yan J, Xia Y, Vetvickova J. Therapeutic intervention with complement and beta-glucan in cancer. Immunopharmacology 1999; 42 (1-3): 61-74.

10. Lee KY, Lee MH, Chang IY, Yoon SP, Lim DY, Jeon YJ. Macrophage activation by polysaccharide fraction isolated from Salicornia herbacea. J Ethnopharmacol 2006; 103 (3): 372-378.

11. Kim MK, Lee IY, Ko JH, Rhee YH, Park YH. Higher intracellular levels of uridinemonophosphate under nitrogen-limited conditions enhance metabolic flux of curdlan synthesis in Agrobacterium species. Biotechnol Bioeng 1999; 62 (3): 317-323.
12. Janeway CA, Jr., Medzhitov R. Innate immune recognition. Annu Rev Immunol 2002; 20: 197-216.

13. Rao KM. MAP kinase activation in macrophages. J Leukoc Biol 2001; 69 (1): 3-10.

14. Brown GD, Gordon S. Immune recognition. A new receptor for betaglucans. Nature. 2001; 413 (6851): 36-37.

15. Tsiapali E, Whaley S, Kalbfleisch J, Ensley HE, Browder IW, Williams DL. Glucans exhibit weak antioxidant activity, but stimulate macrophage free radical activity. Free Radic Biol Med 2001; 30 (4): 393-402.

16. Weight SC, Furness PN, Nicholson ML. New model of renal warm ischaemia-reperfusion injury for comparative functional, morphological and pathophysiological studies. Br J Surg 1998; 85 (12): 1669-1673.

17. Cao G, Prior RL. Comparison of different analytical methods for assessing total antioxidant capacity of human serum. Clin Chem 1998; 44 (6 Pt 1): 1309-1315.

18. Erel O. A novel automated direct measurement method for total antioxidant capacity using a new generation, more stable ABTS radical cation. Clin Biochem 2004; 37 (4): 277-285.

19. Erel O. A new automated colorimetric method for measuring total oxidant status. Clin Biochem 2005; 38 (12): 1103-1111.

20. Hu ML, Louie S, Cross CE, Motchnik P, Halliwell B. Antioxidant protection against hypochlorous acid in human plasma. J Lab Clin Med 1993; 121 (2): 257-262.

21. Klebanoff SJ, Clark RA. The neutrophil: function and clinical disorders. Amster-North Holland Biomedical, 1978.

22. Eckerson HW, Wyte CM, La Du BN. The human serum paraoxonase/ arylesterase polymorphism. Am J Hum Genet 1983; 35 (6): 1126-1138.

23. Aebi H. Catalase. 673-677. In: Bergmeyer HU (Eds). Methods of Enzymatic Analysis. New York and London: Academic Press, 1974.

24. Haagen L, Brock A. A new automated method for phenotyping arylesterase (EC 3.1.1.2) based upon inhibition of enzymatic hydrolysis of 4-nitrophenyl acetate by phenyl acetate. Eur J Clin Chem Clin Biochem 1992; 30 (7): 391-395.

25. Selek S, Aslan M, Horoz M, Gur M, Erel O. Oxidative status and serum PON1 activity in beta-thalassemia minor. Clin Biochem 2007; 40 (5-6): 287-291.

26. Zhang W, Wang YL, Wang HJ, Miao ZH, Xia XH. The effect of vitamin $\mathrm{E}$ on renal ischemia/reperfusion injury in young and aged rats. Zhongguo Ying Yong Sheng Li Xue Za Zhi 2010; 26 (2): 159-163.

27. Eltzschig HK, Eckle T. Ischemia and reperfusion--from mechanism to translation. Nat Med 2011; 17 (11): 1391-401.

28. Heinzelmann M, Mercer-Jones MA, Passmore JC. Neutrophils and renal failure. Am J Kidney Dis 1999; 34 (2): 384-399.

29. Kofuji K, Aoki A, Tsubaki K, Konishi M, Isobe T, Murata Y. Antioxidant Activity of beta-Glucan. ISRN Pharm 2012; 2012: 125864.

30. Wronska-Nofer T, Nofer JR, Stetkiewicz $\mathbf{J}$ et al. Evidence for oxidative stress at elevated plasma thiol levels in chronic exposure to carbon disulfide (CS2) and coronary heart disease. Nutr Metab Cardiovasc Dis 2007; 17 (7): 546-553.

31. Banne AF, Amiri A, Pero RW. Reduced level of serum thiols in patients with a diagnosis of active disease. J Anti Aging Med 2003; 6 (4): $327-334$. 


\section{0-538}

32. Ysebaert DK, De Greef KE, Vercauteren SR et al. Identification and kinetics of leukocytes after severe ischaemia/reperfusion renal injury. Nephrol Dial Transplant 2000; 15 (10): 1562-1574.

33. Nakajima A, Ueda K, Takaoka M, Yoshimi Y, Matsumura Y. Opposite effects of pre- and postischemic treatments with nitric oxide donor on ischemia/reperfusion-induced renal injury. J Pharmacol Exp Ther 2006; 316 (3): 1038-1046.

34. Versteilen AM, Blaauw N, Di Maggio F et al. rho-Kinase inhibition reduces early microvascular leukocyte accumulation in the rat kidney following ischemia-reperfusion injury: roles of nitric oxide and blood flow. Nephron Exp Nephrol 2011; 118 (4): e79-86.

35. Behrends M, Hirose R, Park YH et al. Remote renal injury following partial hepatic ischemia/reperfusion injury in rats. J Gastrointest Surg 2008; 12 (3): 490-495.

36. Koc M, Kumral ZN, Ozkan N et al. Obestatin improves ischemia/reperfusion-induced renal injury in rats via its antioxidant and anti-apoptotic effects: Role of the nitric oxide. Peptides 2014; 60c: 23-31.

37. La Du BN, Aviram M, Billecke $S$ et al. On the physiological role (s) of the paraoxonases. Chem Biol Interact 1999; 119-120: 379-388.

38. Wegner M, Piorunska-Stolzmann M, Araszkiewicz A, ZozulinskaZiolkiewicz D, Wierusz-Wysocka B. Evaluation of paraoxonase 1 arylesterase activity and lipid peroxide levels in patients with type 1 diabetes. Pol Arch Med Wewn 2011; 121 (12): 448-454.
39. Shen H, Robertson LW, Ludewig G. Regulation of paraoxonase 1 (PON1) in PCB 126-exposed male Sprague Dawley rats. Toxicol Lett 2012; 209 (3): 291-298.

40. Gabay C, Kushner I. Acute-phase proteins and other systemic responses to inflammation. N Engl J Med 1999; 340 (6): 448-454.

41. Szalai AJ, van Ginkel FW, Dalrymple SA, Murray R, McGhee JR, Volanakis JE. Testosterone and IL-6 requirements for human C-reactive protein gene expression in transgenic mice. J Immunol 1998; 160 (11): 5294-5299.

42. Hurlimann J, Thorbecke GJ, Hochwald GM. The liver as the site of C-reactive protein formation. J Exp Med 1966; 123 (2): 365-378.

43. Jabs WJ, Logering BA, Gerke P et al. The kidney as a second site of human C-reactive protein formation in vivo. Eur J Immunol 2003; 33 (1): 152-161.

44. Pegues MA, McCrory MA, Zarjou A, Szalai AJ. C-reactive protein exacerbates renal ischemia-reperfusion injury. Ren Physiol 2013; 304 (11): F1358-1365.

45. Yang S, Chou WP, Pei L. Effects of propofol on renal ischemia/reperfusion injury in rats. Exp Ther Med 2013; 6 (5): 1177-1183.

Received April 1, 2016. Accepted April 27, 2016. 